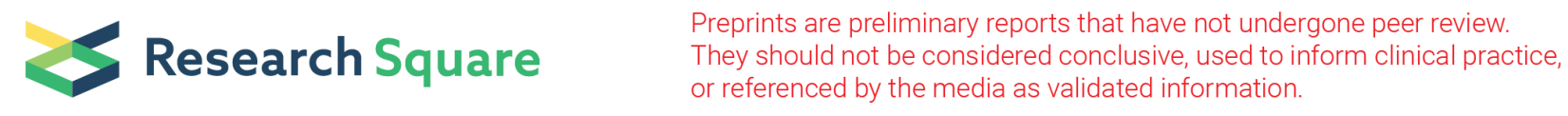

\title{
Prediction of delayed neuro-psychomotor development in infants using brainstem auditory evoked potentials and the Bayley II scales
}

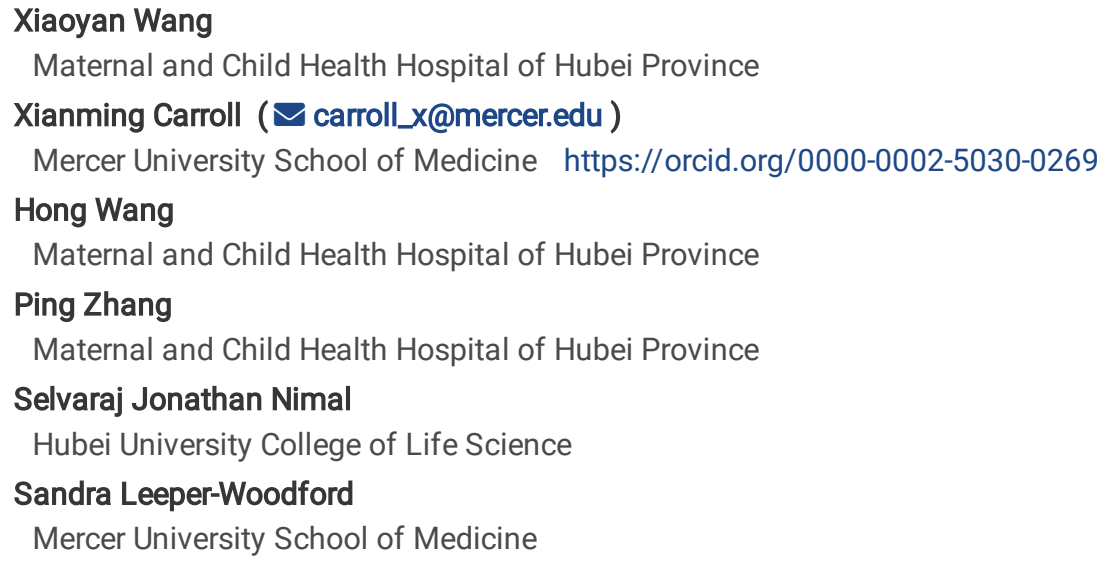

Keywords: Neuro-psychomotor development, Brainstem auditory evoked potentials, Bayley scales of infant development, Premature birth, Perinatal conditions

Posted Date: July 2nd, 2019

DOI: https://doi.org/10.21203/rs.2.10833/v1

License: (c) (1) This work is licensed under a Creative Commons Attribution 4.0 International License. Read Full License 


\section{Abstract}

Background: Delayed neuro-psychomotor development in infants tends to be present more often as a result of perinatal issues such as asphyxia, respiratory failure, and prematurity. Brainstem auditory evoked potentials (BAEP) provide an objective analysis of central nervous system function and development in infants. This study proposed to assess the neuro-psychomotor development in infants affected by perinatal conditions by comparing the results of their BAEP with assessments of development including mental development indices (MDI), a form of Bayley Scales of Infant Development. Methods: The retrospectively selected population included preterm (28-36 weeks gestation; 95 cases) and term infants ( $\geq 37$ weeks gestation; 100 cases) who were born with specific perinatal conditions. The BAEP were recorded in these infants from 1 to 8 months of age, and the MDI were performed in these infants at age 2 years. Chi-square, ANOVA, and student t-tests were used to test significance of BAEP correlations with MDI indices in theses infants. Significance was determined at a p-value $\leq 0.05$. Results: In premature infants (28-32 weeks gestation), 75\% had abnormal BAEP, and MDI at age 2 years were moderately low ( $90.76 \pm 4.1$ ); fewer term infants had abnormal BAEP (24.5\%), and MDI at age 2 years were moderately higher (98.55 \pm 4.6$)$. Preterm infants with abnormal BAEP, and perinatal asphyxia or respiratory failure had low MDI at age 2 years ( $76.36 \pm 3.66$ or $80.36 \pm 7.66$, respectively); $60 \%$ fewer term infants with these perinatal conditions had abnormal BAEP, and their MDI were 3-10\% higher. Our results show that infants experiencing prematurity, perinatal asphyxia or respiratory failure, may have lower scores of neuro-psychomotor development at age 2, if earlier tests reveal abnormal BAEP assessments in these infants. Conclusion: Our study found that premature infants exposed at birth to conditions such as asphyxia and respiratory failure, and exhibiting abnormal BAEP in their first year, may be predicted to present with delayed neuro-psychomotor development. We propose that BAEP may be utilized as a potential indicator for neuro-psychomotor development, and suggest that parental education and early intellectual interventions to enrich cognition development in children with abnormal BAEP should be encouraged.

\section{Background}

There has been a rapid increase in survival rates of premature infants in recent decades because of the advancement in neonatal intensive care. Certain unexpected medical issues occur in newborn infants which affect the long-term learning ability in children [1-4]. If not addressed properly in the early stages of infant development, these medical issues in early infancy can have long-term effects on neural development. Asphyxia during birth could be one of the key issues leading to major neurodevelopmental deficits in early childhood learning. Studies have indicated that during hypoxia, hypoxanthine accumulation generates oxygen radicals, especially in the recovery phase, and this may lead to hypoxia-induced injury due to asphyxia [5].

Studies have also shown that children surviving birth asphyxia develop neurodevelopmental disorders, such as learning and intellectual disabilities [6-7]. Infants treated with resuscitation who survived birth asphyxia may be expected to have normal development until at least age three [8]. Another study indicated that basic resuscitation at birth prevents abnormal neurodevelopmental outcomes at one year of age when compared to low-risk newborns [9]. Other factors, like late-preterm birth (34 to 36 weeks) have also been found to lead to long-term cognitive issues $[10,11]$.

Abnormality in the brainstem auditory evoked potentials (BAEP) is considered to be an early indicator for cognitive related brain issues in preterm and postnatal infants [12]. BAEP may be used to assess auditory function in infants and children, and is a clinically useful method for evaluation of cognitive development [13]. The Bayley scales of infant development (BSID) is considered the best measuring tool for assessing infant developmental progress [14-16]. The BSID-I can be used for assessing infants between two to 30 months of age, and the BSID-II and Bayley-III can assess infants ranging between one to 42 months of age [14-16]. The BSID-II has two scales which include the mental developmental index (MDI) and the psychomotor developmental index (PDI) [14].

In this study, we used BAEP and the BSID II for the assessment of infants born prematurely or at term with diseases or certain medical conditions during the time of delivery. We then analyzed the neuro-psychomotor development of these infants by using their MDI/PDI scores and comparing with the BAEP assessments of these infants. We propose that by using these assessments, we may be able to predict the neuro-psychomotor development of infants exposed to compromising medical conditions at birth.

\section{Methods}

\section{Study population}

This retrospective study from Hubei Provincial Maternal and Child Health Hospital, included preterm infants (95 cases; 28-36 weeks gestational age), and term infants (100 cases; $\geq 37$ weeks gestational age) who were born between June 1st, 2014 to October 31 st, 2015 . All infants included in this study had issues such as asphyxia, respiratory failure, or infection at the time of delivery, and they were followed up to the age 2 years. The assessment form included family status, parental occupation and education, perinatal status, and whether mothers had issues of hypertension, diabetes, or history of miscarriage, threatened abortion, intrauterine distress or jaundice. The study was approved by 
the Ethics Committee of Hubei Provincial Maternal and Child Health Hospital. Informed consent of parents was obtained for all infants. All procedures and methods were performed by the authors in accordance with the approved guidelines.

\section{BAEP assessment}

The auditory function of all infants in this study was assessed with BAEP at 28-41 weeks after birth. The BAEP assessment is considered an effective tool in screening for possible hearing loss in children with conditions such as meningitis, where it has been found that the frequency of BAEP impairment or hearing loss was $34.6 \%$ and $30.8 \%$, respectively [17]. BAEP have been used to assess the hearing abilities in infants 6 months old, and in those older who have motor or intellectual problems [18]. In our study, BAEP were recorded using the Navigator PRO brainstem auditory evoked potential system (Bio-logic Inc., USA). The recording electrode was placed in the midline of the forehead, and the reference electrode was placed at the bilateral mastoid. Electrode impedance was reduced to $<5 \mathrm{k} \Omega$, which was maintained during the whole session of the BAEP recording. The acoustic stimuli were given through TIP-50 earphones using a click sound stimulus. Band pass filter was $0.1 \sim 3 \mathrm{kHz}$, superimposition was 1024-2048 times, and stimulation rate was 30.1 times/second, and the sweep duration was 10 ms.

The BAEP assessments were performed in a sound-insulated room with a noise level below $30 \mathrm{dBA}$. The I, III, V wave latency and I-III, III-V, I-V wave interval were recorded under $80 \mathrm{dBnHL}$ short-sound stimulation. The waves (I-V) are usually recorded in the first $10 \mathrm{~ms}$ following broadband and high-intensity clicks. The latencies of waves I, III, and V, interpeak latencies of I-III, III-V, and I-V, and the amplitude ratio of wave V to wave I are assessed for abnormalities of BAEPs $[16,19]$. Recordings are obtained and compared with respect to midline forehead and mastoids. Evaluating different components of the latencies and amplitudes of the waves allows for evidence of impaired neural function in the auditory brainstem as evidenced by delayed latencies and reduced amplitudes of the component waves [16, 19]. BAEP impairment is determined by latencies of waves I, III, and V that are increased beyond 2 S.D. of age-matched normal infant values, with normal interpeak latencies of I-III, III-V, and I-V, and hearing thresholds elevated to above $40 \mathrm{~dB}$. Abnormal BAEP is also noted by hearing thresholds increased to greater than $40 \mathrm{~dB}$, with normal latencies and interpeak latencies; or increased latencies of wave $\mathrm{V}$ or III (or both) and increased interpeak latencies of waves I-V and III-V, with elevated or normal hearing thresholds $[16,19]$. Duplicate recordings were made in response to each stimulus condition to recheck the reproducibility. BAEP were monitored in infants at 1, 3, 6, and 8 months of age.

\section{Neurodevelopmental assessment}

The Bayley scale of infant development (BSID II) was used for neurodevelopment assessment [14, 15]. The BSID-II has the mental development index (MDI) divided into distinct cognitive, receptive language, and expressive language scales, and the psycho-motor development index (PDI) divided into motor development scales. The MDI indicating the intelligence scale includes adaptive behaviors, language and exploration activities, and the PDI indicates the gross and fine movements [14, 15]. A recent meta-analysis study which reviewed the usage of BSID-II indicated that MDI scores correlated strongly with later cognitive functions, explaining $37 \%$ of variance, while PDI scores indicated later motor outcomes with only $12 \%$ of the variance [19]. In our study, professionally trained medical staff performed the assessments under the same test conditions on children at 1 to 2 years of age that were born either preterm or at full-term. The following scale was used for MDI and PDI score assessment: $\geq 120$ is excellent development; 119 to 90 is moderate development; 80 to 89 is less than moderate development; 70 to 79 is low development; and $\leq 69$ is developmental delay. The relationship between the normal and abnormal BAEP assessment at the 6th and the 8th month of age, and the MDI/PDI scores for neuro-psychomotor development at age 2 years were monitored with respect to different conditions at birth.

\section{Statistical analysis}

Statistical analysis was performed with the Statistical Package for the Social Science System version SPSS 17.0 (Inc, Chicago, IL, USA). First, the clinical characteristics of the samples were outlined at different gestational ages, including delivery mode, birth weight, days of hospitalization, and the perinatal conditions of infection, jaundice, asphyxia, respiratory failure, and intracranial hemorrhage. Second, the Chisquare test was used to test the significance in BAEP abnormalities between term and preterm infants of different gestational ages. This was performed on data from the infants at age 1 month, 3 months, 6 months and 8 months. Third, normally-distributed continuous variables were compared using the ANOVA for the significance of the neurodevelopmental indices, MDI and PDI, between term and preterm infants of different gestational ages. This was performed on data from the infants at age 1 month, 3 months, 6 months and 2 years. The student $t$ test was then used to examine the significance of the MDI neurodevelopmental index at age 2 years, between the preterm and term infants exposed at birth to infection, jaundice, asphyxia, respiratory failure, or intracranial hemorrhage, with respect to whether each of the infants had normal or abnormal BAEP assessments at age 6 months. All statistical tests were considered to be significant at an alpha level of 0.05 on a two-tailed test. 


\section{Results}

\section{Characteristics of study population}

The preterm infants (28-36 weeks gestational age), and term infants ( $\geq 37$ weeks gestational age) enrolled in this study had conditions including infection, jaundice, asphyxia, respiratory failure and intracranial hemorrhage during the time of delivery. Among the 95 preterm infants, the mean gestational age was $34.8 \pm 3.82$ weeks, the mean birth weight was $2.65 \pm 0.41 \mathrm{~kg}$, and the mean hospitalization time was $7.57 \pm 2.35$ days. A number of the preterm and term infants in the study had issues of asphyxia (34.9\%), followed by jaundice (26.7\%), respiratory failure (21.5\%), infection (16.9\%), and intracranial hemorrhage (10.2\%) (Table 1). There were 100 infants born at term (gestational age, 37 - 41 weeks), and birth by Caesarean section was seen in $70 \%$ of the cases in both preterm and term infants (Table 1).

\section{BAEP assessment}

BAEP assessments were recorded in all term and preterm infants included in this study. In preterm infants, abnormal BAEP assessments tended to be increased at age 1 month in those born at 28-32 weeks (85.7\%), 33-34 weeks (100\%), 35-36 weeks (82.6\%) and in term infants (80.7\%) (Table 2). In premature infants born at 28-32 weeks, abnormal BAEP assessments did not improve significantly from the $1^{\text {st }}$ month $(85.7 \%)$ to the $8^{\text {th }}$ month $(75 \%)$. However, a significant improvement in BAEP were observed at age 8 months in infants born at 35-36 weeks gestation $(32 \%)$ and in the infants born at term (24.5\%). Significant differences in the improvement of BAEP at age 8 months were found between infants born at $28-32$ weeks (75\%) and term infants (24.5\%) (Table 2). Our results indicate that abnormal BAEP assessments tend to be higher and that BAEP remains abnormal during the early growth period in preterm infants when compared to BAEP in term infants (Table 2).

\section{Neurodevelopment assessment based on BSID}

The BSID neurodevelopment assessment of the infants varied according to gestational age (Table 3). The MDI/PDI scores in the infants born at 28-32 weeks showed an increased trend from the $1^{\text {st }}$ month $(78.36 \pm 8.51 / 77.08 \pm 8.89)$ to the $6^{\text {th }}$ month $(85.95 \pm 5.73 / 85.33 \pm 7.11)$, and increased further at age 2 years $(90.66 \pm 4.10 / 91.10 \pm 3.26)$ (Table 3). In the infants born at 35-36 weeks, there were also trends for higher $\mathrm{MDI} / \mathrm{PDI}$ scores during the growth period, at 1 month $(81.80 \pm 2.67 / 80.42 \pm 2.64), 6$ months $(87.21 \pm 1.11 / 86.24 \pm 1.15)$, and at age 2 years $(94.13 \pm 4.80 / 94.53 \pm 4.72)$. In the term infants, MDI/PDI scores were higher than in preterm infants at age 1 month, and were increased to a greater extent at age 2 years $(98.55 \pm 4.64 / 99.81 \pm 3.92)$. Overall, these data show that the neurodevelopment of premature infants of different gestational ages gradually increases with age, and that their developmental level gradually approaches that of the term infants (Table 3). However, when compared to the neurodevelopment of term infants at each of the respective age groups, these data also reveal that there are trends for differences in the neurodevelopmental levels of premature infants at 1-month, 3-months, 6-months and 2 years of age (Table 3).

\section{Neurodevelopment associated with BAEP and issues at birth}

Issues like diseases or conditions at birth may impact the BAEP scores in both preterm and term infants (Table 4). In preterm infants who experienced asphyxia, the number of abnormal BAEP cases at age 6 months (32 infants) was higher, and the MDI scores were significantly lower in this group at age 2 years $(76.36 \pm 3.66)$, when compared to those preterm infants with asphyxia at birth who were assessed with normal BAEP (10 infants; MDI scores, $82.30 \pm 5.67$ ) (Table 4). Similarly, in term infants with asphyxia at birth and abnormal BAEP at age 6 months (13 infants), lower MDI scores were observed at age 2 years (83.12 \pm 5.66$)$, but significantly higher MDI scores were observed in the 13 infants with asphyxia at birth and normal BAEP $(93.42 \pm 5.45)$ (Table 4$)$. In the preterm infants who experienced respiratory failure at birth, the $\mathrm{MDI}$ at age 2 years was $80.36 \pm 7.66$ in those with abnormal BAEP at age 6 months ( 25 infants), but the MDI showed higher scores in those 10 preterm infants with respiratory failure at birth and normal BAEP $(84.44 \pm 5.55)$. In preterm infants who had issues such as infection, jaundice and intracranial bleeding at birth, the MDI scores at age 2 were significantly higher in those infants with normal BAEP $(89.75 \pm 5.25,94.30 \pm$ 7.74 , and $92.28 \pm 4.52$, respectively) (Table 4). With respect to infection, jaundice and intracranial bleeding issues at birth, similar patterns were observed in the MDI scores of term infants with normal BAEP (respectively, $93.89 \pm 9.75 ; 93.62 \pm 5.66$; $93.32 \pm 5.31$ ) (Table 4).

\section{Discussion}

There is increasing evidence that the issues related to child mental and motor function performance in the early infant stages are related to conditions or diseases during preterm or term birth $[1,20]$. Our study provides evidence that premature infants have issues of mental and motor function performance following exposure to asphyxia, respiratory failure, jaundice, infection and intracranial bleeding. These infants 
exhibited higher levels of abnormal BAEP, auditory function scores in the first year of infancy, and this is correlated with their lower MDI/PDI scores in the BSID, indicators of mental and psychomotor development. Our results indicate that abnormal BAEP could be a potential indicator for altered mental and motor function at later ages. The majority of preterm infants who experienced asphyxia at birth and had abnormal BAEP at 6 months of age, exhibited lower MDI/PDI scores, suggesting that there may be altered mental and psychomotor functions, especially in language development in these infants at age 2.

In our study, we used the modified Bayley II scale which is used in Chinese hospitals to assess the neurodevelopment in premature infants. Our results utilizing the Bayley-ll scale showed good predictability for infant neurodevelopment, yet further studies are needed to compare with assessments reported using the Bayley III scale. Previous studies have shown that the Bayley-III scale could be effective in measuring developmental functions with respect to examiner observations, and parent-reported behaviours [21]. But, while this scale may be used to collectively assess language development, many larger studies are needed to prove its effectiveness [21]. Previous publications have indicated that the BSID-II has higher predictive abilities for future functioning, while others favour Bayley-III [22, 23]. There are indications that BSID-II might underestimate development and BSID-III might overestimate development [24]. The Bayley III scale identified significantly fewer children with disabilities with respect to low birth weight preterm infants, and the authors proposed that intervention may be essential for these infants at the time of discharge from the neonatal intensive care unit $[25,26]$. The Bayley-II and brain magnetic resonance imaging to assess the neurodevelopmental outcomes have mostly been applied to infants exposed to asphyxia [27, 28]. In our study using the Bayley-II application, we identified a number of cases with neurodevelopmental issues especially in the infants exposed to asphyxia and respiratory failure.

In a previous study on infant brain damage due to total asphyxia, the magnetic resonance imaging of the brain indicated abnormal intensity of the putamen and thalamus, with atrophy in the brainstem [29]. Other studies showing magnetic resonance imaging in newborns exposed to asphyxia indicated lesions in basal ganglia, thalamus, brainstem tectum, parasagittal cortex and midline cerebrum, but found no lesions in basal ganglia and parasagittal regions [30]. Perinatal hypoxemia has also been shown to damage the neonatal auditory system, including the cochlea and auditory pathways in the brain' which then leads to hearing deficits [30]. Children suffering from perinatal asphyxia tend to exhibit hearing loss with residual neurodevelopmental deficits when compared to those not exposed to asphyxia [31, 32]. Previous studies showed that perinatal asphyxia often produces discrete lesions in the generators of brainstem auditory-evoked response central components, the cochlear nuclei, superior olive, and inferior colliculus, and that brainstem auditory-evoked response abnormalities occurred more frequently in those after severe, prolonged asphyxia [30,33]. In several clinical cases of perinatal asphyxia, he infants generally recovered without neurological disorder, but some exhibited residual neurodevelopmental deficits due to hypoxic-ischemic conditions in their brains [33, 34]. In our study, the data revealed abnormal brainstem auditory-evoked responses in infants exposed to perinatal conditions such as asphyxia and respiratory failure, and that this auditory assessment may be used to predict delays in their neuro-psychomotor development.

The MDI/PDI scores of mental and psychomotor function vary during the stages of early infant development $[35,36]$. A previous study indicated that variation in the PDI score for psychomotor function is less significant compared to the MDI score for mental function in low birth weight infants [36]. In our study, however, there was a steady increase in the MDI/PDI scores from age 1 month to 2 years in early preterm infants, and there was little significant variation in the scores of term infants at each of these respective age groups. We also observed significant greater increases in MDI scores in early preterm (< 32 weeks) infants, when compared to those of late preterm (33-36 weeks) infants. Similar variations in the PDI scores of these infants were also observed. These results are consistent with other studies [37]. Interestingly we found that preterm infants exposed to asphyxia with abnormal BAEP in the first few months had significantly lower MDI scores, compared to those of term infants exposed to asphyxia. This may be due to early interventions in the infants born at term.

Studies using the Bayley II scale consistently identified high rates of cognitive impairments among preterm or low birth rate infants [38]. In our study, the cognitive impairments tend be higher in preterm infants subjected to asphyxia or respiratory failure based on the Bayley II assessment. Other studies have shown that there is a reduction in cognitive impairment level from $39 \%$ at 20 months to $16 \%$ at 8 years, based on the Bayley II assessment in extremely low birth weight infants [39]. The MDI/PDI values for mental and motor scores that were observed at age 2 years in our study could have shown increases at the later stage of development, if these infants had been exposed to early interventions to improve their developmental skills.

In a study where interventions supporting parent-child interactions to enhance motor control and coordination, are provided weekly at home from the age of six months to 12 months, the overall cognitive level, especially in verbal performance was higher at age 4 . We therefore propose that to improve their cognitive level during the stages of infant growth, early interventions are highly essential in infants with low MDI/PDI scores. In a previous publication, high doses of DHA supplementation were given at an early age, and was found to be beneficial for improving mental development, especially in girls $[40,41]$. Studies on low birth weight infants showed that their behavioral characteristics are also affected by family socioeconomic status, which may play a role in delayed cognitive developmental at 18-22 months [42-44].

There are some limitations in our studies. One is the limited number of preterm infants with disease or conditions at birth enrolled in our study to examine the MDI/PDI scores. Another limitation may be our use of the Bayley II scale in the assessments because the Bayley III scale might 
reveal different results with respect to the current data. Larger scale, long-term studies are also needed to provide further investigations concerning neurodevelopmental outcomes from birth to childhood. In addition, issues related to gender or parent socioeconomic conditions may need to be taken into consideration in future studies.

\section{Conclusions}

Our study found that premature infants exposed to conditions such as asphyxia and respiratory failure at birth exhibited abnormal BAEP auditory function scores, and also lower MDI/PDI indicators of mental and psychomotor development during the first year of infancy. These infants also showed less improvement in language and cognitive development at the later developmental stages. Preventive prenatal care and early diagnoses and treatments during the perinatal period could help prevent later problems with neuro-psychomotor development in early childhood. In addition, certain early intellectual interventions like parental education with respect to skills and games to enrich infant learning may facilitate cognitive and motor development in babies with abnormal BAEP scores and lower MDI/PDI scores. For infants who experience asphyxia, respiratory failure, or other compromising conditions at birth, early interventions to improve cognitive and motor skills development for these infants might help to attenuate the abnormal neuro-psychomotor issues that develop at later stages in both premature infants, and in those born at term.

\section{Abbreviations}

BAEP: Brainstem auditory evoked potentials; BSID: Bayley scales of infant development; MDI: Mental development index; PDI: Psychomotor developmental index

\section{Declarations}

\section{Acknowledgments}

We are particularly grateful to all the pediatricians, nurses who participated in patient recruitment and data collection at Hubei Provincial Maternal and Child Health Hospital.

\section{Authors' contributions}

XYW designed the study, performed the experiments, and helped with manuscript preparation. XMC helped with statistical analysis, revised the subsequent drafts of the manuscript, and was responsible for the final submission. HW provided general support for the research project. PZ collected and analyzed the data. SJN wrote the first draft of the manuscript. SLW reviewed and edited the subsequent drafts of the manuscript. All authors read and approved the final version of the manuscript.

\section{Funding}

The research has been supported by the China Center for Disease Control and Prevention for the technology research projects for early childhood development from 2017 to 2018 (2017FYE004). The funding source had no role in the study design, data collection, statistical analysis, data interpretation, or writing the manuscript.

\section{Availability of data and materials}

The data analyzed during the current study are not publicly available because they include personal identifiers and medical information that cannot be released, but are available from the first author on reasonable request.

\section{Ethics approval and consent to participate}

This study was approved by the Institutional Ethics Committee of Hubei Provincial Maternal and Child Health Hospital. Written informed consent was obtained from each study participant. All the information obtained from the study participants were kept confidential throughout the process of study, and the name of the participant was replaced by code. Withdrawal from the study at any point if they wished was assured. 


\section{Consent for publication}

Not applicable.

\section{Competing interests}

The authors declare that they have no competing interests.

\section{References}

1. Marlow N, Hennessy EM, Bracewell MA, Wolke D, EPICure Study Group. Motor and executive function at 6 years of age after extremely preterm birth. Pediatrics. 2007;120(4):793-804.

2. Sammallahti S, Pyhälä R, Lahti M, Lahti J, Pesonen AK,et al. Infant growth after preterm birth and neurocognitive abilities in young adulthood. J Pediatr.2014;165(6):1109-1115.e3.

3. Wood N, Costeloe K, A Gibson A, Hennessy E, Marlow N, et al. The EPICure study: associations and antecedents of neurological and developmental disability at 30 months of age following extremely preterm birth.Arch Dis Child Fetal Neonatal Ed. 2005;90(2): F134-F140.

4. Vohr BR, Wright LL, Dusick AM, Mele L, Verter J, et al. Neurodevelopmental and functional outcomes of extremely low birth weight infants in the national institute of child health and human development neonatal research network, 1993-1994. Pediatrics. 2000;105(6):12161226.

5. Saugstad OD. Hypoxanthine as an indicator of hypoxia: its role in health and disease through free radical production. Pediatr Res. 1988;23(2):143-150.

6. Pierrat V, Haouari N, Liska A, Thomas D, Subtil D, et al. Prevalence, causes, and outcome at 2 years of age of newborn encephalopathy: population based study. Arch Dis Child Fetal Neonatal Ed. 2005;90(3):F257-F261.

7. Al-Macki N, Miller SP, Hall N, Shevell M. The spectrum of abnormal neurologic outcomes subsequent to term intrapartum asphyxia. Pediatr Neurol.2009;41(6):399-405.

8. Wallander JL, Bann C, Chomba E, Goudar SS, Pasha O, et al. Developmental trajectories of children with birth asphyxia through 36 months of age in low/low-middle income countries. Early Hum Dev. 2014;90(7):343-348.

9. Janet S, Carrara VI, Simpson JA, Thin NWW, Say WW, et al. Early neonatal mortality and neurological outcomes of neonatal resuscitation in a resource-limited setting on the Thailand-Myanmar border: a descriptive study. PLoS One. 2018;13(1):e0190419.

10. Talge NM, Holzman C, Wang J, Lucia V, Gardiner J, et al. Breslau N.Late-preterm birth and its association with cognitive and socioemotional outcomes at 6 years of age. Pediatrics. 2010;126(6):1124-1131.

11. Petrini JR, Dias T, McCormick MC, Massolo ML, Green NS, et al. Increased risk of adverse neurological development for late preterm infants. J Pediatr. 2009;154(2):169-176.

12. Karmel BZ, Gardner JM, Zappulla RA, Magnano CL, Brown EG. Brain-stem auditory evoked responses as indicators of early brain insult. Electroencephalogr Clin Neurophysiol. 1988;71(6):429-442.

13. Bao X, Wong V. Brainstem auditory-evoked potential evaluation in children with meningitis. Pediatr Neurol. 1998;19(2):109-112.

14. Bayley N. Bayley Scales of Infant Development, 2nd ed. (The Psychological Corporation; San Antonio, TX, 1993).

15. Sattler JM, Dumont R. Assessment of children. (Jerome M. Sattler; San Diego, CA, 1992).

16. Bayley N. Bayley Scales of Infant and Toddler Development 3rd Edition (Bayley-III). (The Psychological Corporation; San Antonio, TX, 2006).

17. Martínez-Cruz CF, Poblano A, Fernández-Carrocera LA. Risk factors associated with sensorineural hearing loss in infants at the neonatal intensive care unit: 15-year experience at the National Institute of Perinatology (Mexico city). Arch Med Res. 2008;39(7):686-694.

18. American Academy of Pediatrics, Joint Committee on Infant Hearing. Year 2007 position statement: Principles and guidelines for early hearing detection and intervention programs. Pediatrics. 2007;120(4):898-921.

19. Luttikhuizen Dos Santos ES, de Kieviet JF, Konigs M, van Elburg RM, Oosterlaan J. Predictive value of the Bayley scales of infant development on development of very preterm/very low birth weight children: a meta-analysis. Early Hum Dev. 2013;89(7): 487-496.

20. Anderson P, Doyle LW, Victorian Infant Collaborative Study Group. Neurobehavioral outcomes of school-age children born extremely low birth weight or very preterm in the 1990s. JAMA. 2003;289(24):3264-3272.

21. Messinger $D$, et al. The relationship between behavior ratings and concurrent and subsequent mental and motor performance in toddlers born at extremely low birth weight. J Early Interv. 2010;32(3): 214-233.

Page $7 / 10$ 
22. Moore T, Johnson S, Haider S, Hennessy E, Marlow N. Relationship between test scores using the second and third editions of the bayley scales in extremely preterm children. J Pediatr. 2012;160(4):553-558.

23. Lowe JR, Erickson SJ, Schrader R, Duncan AF. Comparison of the Bayley II mental developmental index and the Bayley III cognitive scale: Are we measuring the same thing? Acta Paediatr. 2012;101:e55-8.

24. Bos AF. Bayley-II or Bayley-III: What do the scores tell us? Dev Med Child Neurol. 2013;55(11):978-979.

25. Vohr BR, Stephens BE, Higgins RD, Bann CM, Hintz SR, et al. Are outcomes of extremely preterm infants improving? Impact of bayley assessment on outcomes. J Pediatr. 2012;161(2):222-228, e3.

26. Huggard D, Slevin M, Vavasseur C. Neurodevelopmental outcome of preterm babies of 1999-2009. Ir Med J. 2014;107(6):166-168.

27. Barkovich AJ, Hajnal BL, Vigneron D, Sola A, Partridge JC, et al. Prediction of neuromotor outcome in perinatal asphyxia: evaluation of MR scoring systems. AJNR Am J Neuroradiol. 1998;19(1):143-149.

28. Miller SP, Ramaswamy V, Michelson D, Barkovich AJ, Holshouser B, et al. Patterns of brain injury in term neonatal encephalopathy. J Pediatr. 2005;146(4):453-460.

29. Natsume J, Watanabe K, Kuno K, Hayakawa F, Hashizume Y. Clinical, neurophysiologic, and neuropathological features of an infant with brain damage of total asphyxia type (Myers). Pediatr Neurol. 1995;13(1):61-64.

30. Pasternak JF, Predey TA, Mikhael MA. Neonatal asphyxia: vulnerability of basal ganglia, thalamus, and brainstem. Pediatr Neurol. 1991;7(2):147-149.

31. Jiang ZD. Long-term effect of perinatal and postnatal asphyxia on developing human auditory brainstem responses: peripheral hearing loss. Int J Pediatr Otorhinolaryngol. 1995;33(3):225-238.

32. Zhang L, Jiang ZD. Development of the brainstem auditory pathway in low birthweight and perinatally asphyxiated children with neurological sequelae. Early Hum Dev. 1992;30(1):61-73.

33. Jiang ZD, Liu XY, Shi BP, Lin L, Bu CF, et al. Brainstem auditory outcomes and correlation with neurodevelopment after perinatal asphyxia. Pediatr Neurol. 2008;39(3): 189-195.

34. Jiang ZD, Chen C. Short-term outcome of functional integrity of the auditory brainstem in term infants who suffer perinatal asphyxia. J Neurol Sci. 2017;376:219-224.

35. Lowe J, Woodward B, Papile LA. Emotional regulation and its impact on development in extremely low birth weight infants. J Dev Behav Pediatr. 2005;26(3):209-213.

36. Lowe J, Erickson SJ, Maclean P. Cognitive correlates in toddlers born very low birth weight and full-term. Infant Behav Dev. 2010;33(4):629-634.

37. Sajaniemi N, Mäkelä J, Salokorpi T, von Wendt L, Hämäläinen T, et al. Cognitive performance and attachment patterns at four years of age in extremely low birth weight infants after early intervention. Eur Child Adolesc Psychiatry. 2001;10(2):122-129.

38. Stoll BJ, Hansen NI, Bell EF, Shankaran S, Laptook AR, et al. Neonatal outcomes of extremely preterm infants from the NICHD Neonatal Research Network. Pediatrics. 2010;126(3):443-56.

39. Galicia-Connolly E, Shamseer L, Vohra S. Complementary, holistic, and integrative medicine: therapies for neurodevelopment in preterm infants. Pediatr Rev. 2012;33(6): 276-278.

40. Lauritzen L, Brambilla P, Mazzocchi A, Harsløf LB, Ciappolino V, et al. DHA effects in brain development and function. Nutrients. 2016; 8(1):6. https://doi.org/10.3390/nu8010006.

41. Innis SM. Dietary (n-3) fatty acids and brain development. J Nutr. 2007,137(4):855-859.

42. Hack M, Taylor HG, Drotar D, Schluchter M, Cartar L, et al. Poor predictive validity of the Bayley scales of infant development for cognitive function of extremely low birth weight children at school age. Pediatrics. 2005;116(2):333-341.

43. Ross GS, Foran L M, Barbot B, Sossin KM, Perlman JM. Using cluster analysis to provide new insights into development of very low birthweight (VLBW) premature infants. Early Hum Dev. 2016;92:45-49.

44. Goodwin LK, lannacchione MA, Hammond WE, Crockett P, Maher S, et al. Data mining methods find demographic predictors of preterm birth. Nurs Res. 2001;50(6):340-345.

\section{Tables}

Table 1. Clinical characteristics of 95 preterm infants and 100 term infants. 


\begin{tabular}{|c|c|c|c|c|c|c|c|c|c|}
\hline \multirow{2}{*}{$\begin{array}{l}\text { Gestational } \\
\text { age(n) }\end{array}$} & \multicolumn{2}{|c|}{ Delivery mode n (\%) } & \multirow{2}{*}{$\begin{array}{c}\text { Birth } \\
\text { weight } \\
\text { (g) }\end{array}$} & \multirow{2}{*}{$\begin{array}{c}\text { Days of } \\
\text { hospitalization }\end{array}$} & \multirow{2}{*}{\begin{tabular}{|c|} 
Infection \\
n (\%)
\end{tabular}} & \multirow{2}{*}{\begin{tabular}{|c|} 
Jaundice \\
$\mathbf{n}(\%)$ \\
\end{tabular}} & \multirow{2}{*}{\begin{tabular}{|c|} 
Asphyxia \\
n (\%) \\
\end{tabular}} & \multirow{2}{*}{$\begin{array}{c}\text { Respiratory } \\
\text { failure } \\
\text { n (\%) }\end{array}$} & \multirow{2}{*}{\begin{tabular}{|c|}
$\begin{array}{l}\text { Intracranial } \\
\text { hemorrhage }\end{array}$ \\
$\mathbf{n}(\%)$
\end{tabular}} \\
\hline & $\begin{array}{l}\text { Vaginal } \\
\text { delivery }\end{array}$ & $\begin{array}{c}\text { Caesarean } \\
\text { birth }\end{array}$ & & & & & & & \\
\hline $\begin{array}{c}28-32 \\
\text { weeks (25) }\end{array}$ & $8(4$. & $\begin{array}{c}17 \\
(17.9 \%) \\
\end{array}$ & $\begin{array}{l}1970- \\
2415 \\
\end{array}$ & $7-22$ & $\begin{array}{c}15 \\
(7.7 \%) \\
\end{array}$ & $\begin{array}{c}22 \\
(11.3 \%) \\
\end{array}$ & $\begin{array}{c}17 \\
(8.7 \%) \\
\end{array}$ & $13(6.7 \%)$ & $8(4.1 \%)$ \\
\hline $\begin{array}{c}33-34 \\
\text { weeks (28) }\end{array}$ & $9(4.6 \%)$ & $19(9.7 \%)$ & $\begin{array}{l}1850- \\
2557\end{array}$ & $5-15$ & $\begin{array}{c}12 \\
(6.2 \%)\end{array}$ & $\begin{array}{c}15 \\
(7.7 \%)\end{array}$ & $\begin{array}{c}13 \\
(6.7 \%)\end{array}$ & $15(7.7 \%)$ & 7( \\
\hline $\begin{array}{c}35-36 \\
\text { weeks (42) }\end{array}$ & $13(6.7 \%)$ & $\begin{array}{c}29 \\
(14.9 \%) \\
\end{array}$ & $\begin{array}{l}2490- \\
3102 \\
\end{array}$ & 3-7 & $3(1.5 \%)$ & $5(2.6 \%)$ & $\begin{array}{c}12 \\
(6.2 \%) \\
\end{array}$ & 7 (3.6\%) & $3(1.5 \%)$ \\
\hline $\begin{array}{l}\geq 37 \\
\text { weeks } \\
(100)\end{array}$ & $\begin{array}{c}18 \\
(9.2 \%)\end{array}$ & $\begin{array}{c}82 \\
(32.9 \%)\end{array}$ & $\begin{array}{l}2900- \\
4100\end{array}$ & $1-7$ & $3(1.5 \%)$ & $\begin{array}{c}10 \\
(5.1 \%)\end{array}$ & $\begin{array}{c}26 \\
(13.3 \%)\end{array}$ & 7 (3.6\%) & $2(1.0 \%)$ \\
\hline Total n (\%) & $\begin{array}{c}48 \\
(24.6 \%) \\
\end{array}$ & $147(75 \%)$ & & & $\begin{array}{c}33 \\
(16.9 \%)\end{array}$ & $\begin{array}{c}52 \\
(26.7 \%)\end{array}$ & $\begin{array}{c}68 \\
(34.9 \%) \\
\end{array}$ & $42(21.5 \%)$ & $20(10.2 \%)$ \\
\hline
\end{tabular}

Term infants, $\geq 37$ weeks gestational age; Preterm infants, 28-36 weeks gestational age

Table 2. Brainstem Auditory Evoked Potential (BAEP) assessment for 95 preterm infants and 100 term infants.

\begin{tabular}{|c|c|c|c|c|}
\hline Gestational age (n) & $\begin{array}{c}\text { Abnormal BAEP cases } \\
\text { at age 1 month } \\
\mathbf{n}(\%)\end{array}$ & $\begin{array}{c}\text { Abnormal BAEP cases } \\
\text { at age 3 months } \\
\mathbf{n}(\mathbf{\%})\end{array}$ & $\begin{array}{c}\text { Abnormal BAEP cases } \\
\text { at age 6 months } \\
\mathbf{n}(\mathbf{\%})\end{array}$ & $\begin{array}{c}\text { Abnormal BAEP cases } \\
\text { at age 8 months } \\
\mathbf{n}(\%)\end{array}$ \\
\hline $\mathbf{2 8 - 3 2}$ weeks (25) & $22(85.7 \%)$ & $21(82.7 \%)$ & $20(80.0 \%)$ & $19(75.0 \%)$ \\
\hline $\mathbf{3 3 - 3 4}$ weeks (28) & $28(100.0 \%)$ & $17(61.8 \%)$ & $16(57.0 \%)$ & $13(45.0 \%)$ \\
\hline $\mathbf{3 5 - 3 6}$ weeks (42) & $35(82.6 \%)$ & $20(47.4 \%)$ & $17(42.0 \%)$ & $13(32.0 \%)$ \\
\hline $\mathbf{3 7}$ weeks (100) & $81(80.7 \%)$ & $61(60.5 \%)$ & $54(54.1 \%)$ & $25(24.5 \%)$ \\
\hline $\mathbf{2}$ values & 2.16 & 7.62 & 6.55 & 8.79 \\
\hline *p-value & 0.080 & 0.001 & 0.005 & $<.0001$ \\
\hline
\end{tabular}

Term infants, $\geq 37$ weeks gestational age; Preterm infants, 28-36 weeks gestational age.*P-value was obtained from chisquare test for categorical variables. Significant level $\mathrm{p} \leq 0.05$

Table 3. Neurodevelopment assessment for 95 preterm infants and 100 term infants by Bayley Scale of Infant Development (BSID II).

\begin{tabular}{|c|c|c|c|c|}
\hline $\begin{array}{c}\text { Gestational age } \\
\text { (n) }\end{array}$ & $\begin{array}{c}\text { MDI/PDI at age } 1 \\
\text { month } \\
(\text { mean } \pm S D)\end{array}$ & $\begin{array}{c}\text { MDI/PDI at age } 3 \\
\text { months } \\
(\text { mean } \pm \text { SD })\end{array}$ & $\begin{array}{c}\text { MDI/PDI at age } 6 \\
\text { months } \\
(\text { mean } \pm S D)\end{array}$ & $\begin{array}{c}\text { MDI/PDI at age } 2 \text { yrs } \\
(\text { mean } \pm S D)\end{array}$ \\
\hline $\begin{array}{c}\text { 28-32 weeks } \\
\text { (25) }\end{array}$ & $\begin{array}{c}78.36 \pm 8.51 / 77.08 \pm \\
8.89\end{array}$ & $\begin{aligned} & 82.60 \pm 4.65 / 80.05 \pm \\
& 5.31\end{aligned}$ & $\begin{array}{c}85.95 \pm 5.73 / 85.33 \pm \\
7.11\end{array}$ & $\begin{array}{c}90.76 \pm 4.10 / 91.10 \pm \\
3.26\end{array}$ \\
\hline $\begin{array}{c}\text { 33-34 weeks } \\
\text { (28) }\end{array}$ & $\begin{aligned} 80.98 \pm & 6.00 / 79.70 \pm \\
& 5.58\end{aligned}$ & $\begin{array}{c}85.76 \pm 4.91 / 85.10 \pm \\
4.10\end{array}$ & $\begin{array}{c}86.57 \pm 2.35 / 85.26 \pm \\
2.60\end{array}$ & $\begin{aligned} 90.93 \pm & 5.57 / 94.36 \pm \\
& 6.67\end{aligned}$ \\
\hline $\begin{array}{c}\text { 35-36 weeks } \\
(42)\end{array}$ & $\begin{array}{c}81.80 \pm 2.67 / 80.42 \pm \\
2.64\end{array}$ & $\begin{array}{c}84.96 \pm 2.20 / 84.38 \pm \\
2.44\end{array}$ & $87.21 \pm \frac{1.11 / 86.24 \pm}{1.15}$ & $\begin{array}{c}94.13 \pm 4.80 / 94.53 \pm \\
4.72\end{array}$ \\
\hline$\geq 37$ weeks (100) & $\begin{array}{c}90.22 \pm 2.18 / 90.61 \pm \\
3.26 \\
\end{array}$ & $\begin{array}{c}91.11 \pm 3.35 / 90.87 \pm \\
2.59 \\
\end{array}$ & 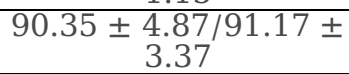 & $\begin{array}{c}98.55 \pm 4.64 / 99.81 \pm \\
3.92\end{array}$ \\
\hline F-value & $73.19 / 93.97$ & $101.96 / 47.57$ & $47.96 / 101.47$ & $18.10 / 27.87$ \\
\hline *p-value & $<.0001 /<.0001$ & $<.0001 /<.0001$ & $<.0001 /<.0001$ & $<.0001 /<.0001$ \\
\hline
\end{tabular}

Term infants, $\geq 37$ weeks gestational age; Preterm infants, 28-36 weeks gestational age. MDI: Mental Development Index; PDI: Psychomotor Development Index MDI or PDI Index: $\geq 120$ is excellent, 119 to 90 is moderate development, 80 to 89 is less than moderate, 70 to 79 is low, and $\leq 69$ is developmental delay. *P-value was obtained from Anova. Significant level $\mathrm{p}$ $\leq 0.05$

Table 4. Brainstem Auditory Evoked Potential (BAEP) at age 6 months versus Mental Development Index (MDI) at age 2 years in preterm infants and term infants with respect to disease/condition at birth. 


\begin{tabular}{|c|c|c|c|c|c|c|}
\hline $\begin{array}{l}\text { Gestational } \\
\text { age } \\
\text { (weeks) }\end{array}$ & Disease/condition & $\begin{array}{c}\text { Abnormal BAEP cases } \\
\text { at age } 6 \text { months } \\
n(\%)\end{array}$ & $\begin{array}{l}\text { MDI at age } \\
2 \text { years } \\
\text { (mean } \pm \\
\text { SD) }\end{array}$ & $\begin{array}{c}\text { Normal BAEP cases at } \\
\text { age } 6 \text { months } \\
n(\%)\end{array}$ & $\begin{array}{l}\text { MDI at age } \\
2 \text { years } \\
\text { (mean } \pm \\
\text { SD) }\end{array}$ & $\begin{array}{c}* \mathrm{p}- \\
\text { value }\end{array}$ \\
\hline \multirow[t]{5}{*}{$28-36$} & Infection & $2(0.1 \%)$ & $\begin{array}{c}80.63 \pm \\
5.21\end{array}$ & $28(14.4 \%)$ & $\begin{array}{c}89.75 \pm \\
5.25\end{array}$ & 0.086 \\
\hline & Jaundice & $3(1.5 \%)$ & $\begin{array}{c}83.43 \pm \\
3.56 \\
\end{array}$ & $39(20.0 \%)$ & $\begin{array}{c}94.30 \pm \\
7.74\end{array}$ & 0.054 \\
\hline & Asphyxia & $32(16.4 \%)$ & $\begin{array}{c}76.36 \pm \\
3.66\end{array}$ & $10(5.1 \%)$ & $\begin{array}{c}82.30 \pm \\
5.67\end{array}$ & $<.0001$ \\
\hline & $\begin{array}{l}\text { Respiratory } \\
\text { failure }\end{array}$ & $25(12.8 \%)$ & $\begin{array}{c}80.36 \pm \\
7.66\end{array}$ & $10(5.1 \%)$ & $\begin{array}{c}84.44 \pm \\
5.55\end{array}$ & 0.004 \\
\hline & $\begin{array}{c}\text { Intracranial } \\
\text { bleeding }\end{array}$ & $2(0.1 \%)$ & $\begin{array}{c}90.35 \pm \\
7.57 \\
\end{array}$ & $16(8.2 \%)$ & $\begin{array}{c}92.28 \pm \\
4.52 \\
\end{array}$ & 0.065 \\
\hline \multirow[t]{5}{*}{$\geq 37$} & Infection & $1(0.5 \%)$ & 90 & $2(0.1 \%)$ & $\begin{array}{c}93.89 \pm \\
9.75\end{array}$ & 0.102 \\
\hline & Jaundice & $1(0.5 \%)$ & 92 & $9(18.0 \%)$ & $\begin{array}{c}93.62 \pm \\
5.66\end{array}$ & 0.203 \\
\hline & Asphyxia & $13(6.7 \%)$ & $\begin{array}{c}83.12 \pm \\
5.66\end{array}$ & $13(6.7 \%)$ & $\begin{array}{c}93.42 \pm \\
5.45\end{array}$ & $<.0001$ \\
\hline & $\begin{array}{l}\text { Respiratory } \\
\text { failure }\end{array}$ & $5(2.6 \%)$ & $\begin{array}{c}81.15 \pm \\
5.64\end{array}$ & $2(0.1 \%)$ & $\begin{array}{c}95.78 \pm \\
4.52\end{array}$ & $<.0001$ \\
\hline & $\begin{array}{c}\text { Intracranial } \\
\text { bleeding }\end{array}$ & $1(0.5 \%)$ & 90 & $1(0.5 \%)$ & $\begin{array}{c}93.32 \pm \\
5.31 \\
\end{array}$ & 0.074 \\
\hline
\end{tabular}

Term infants, $\geq 37$ weeks gestational age; Preterm infants, 28-36 weeks gestational age. MDI Index: $\geq 120$ is excellent, 119 to 90 is moderate development, 80 to 89 is less than moderate, 70 to 79 is low, and $\leq 69$ is developmental delay. $*$ P-value was obtained from student t-test. Significant level $\mathrm{p} \leq 0.05$ 